\title{
Factors Influencing Triacetone Triperoxide (TATP) and \\ Diacetone Diperoxide (DADP) Formation: Part I
}

\author{
Jimmie C. Oxley ${ }^{* a}$; James L. Smith ${ }^{\text {a }}$ Patrick R. Bowden ${ }^{\text {; }}$ Ryan C. Rettinger ${ }^{a}$ \\ ${ }^{a}$ University of Rhode Island, \\ Chemistry Department \\ 51 Lower College Road \\ Kingston, RI 02881 \\ *joxley@chm.uri.edu \\ ${ }^{b}$ Los Alamos National Laboratory, MS P952, \\ Los Alamos, NM, 87545
}

\begin{abstract}
Conditions which result in the formation of triacetone triperoxide (TATP) or diacetone diperoxide (DADP) from acetone and hydrogen peroxide (HP) have been studied for the purposes of inhibiting the reaction. Reaction of HP with acetone precipitates either DADP or TATP, but the overall yield and amount of each was found to depend on (1) reaction temperature; (2) the molar ratio of acid to HP/acetone; (3) initial concentrations of reactants, and (4) length of reaction. Controlling molar ratios and concentrations of starting materials was complicated because both sulfuric acid and hydrogen peroxide were aqueous solutions. Temperature exercised great control over the reaction outcome. Holding all molar concentrations constant and raising the temperature from 5 to $25^{\circ} \mathrm{C}$ showed an increase of DADP over TATP formation and a decrease in overall yield. At $25^{\circ} \mathrm{C}$ a good yield of TATP was obtained if the HP to acetone ratio was kept between 0.5-to-1 and 2-to-1. At constant temperature and HP-toacetone held at one-to-one ratio, acid-to-HP molar ratios between 0.10:1 and 1.2:1 produced good yield of TATP. Plotting the molality of HP versus that of sulfuric acid revealed regions in which relatively pure DADP or pure TATP could be obtained. In addition to varying reaction conditions, adulterants placed into acetone were tested to inhibit the formation of TATP.
\end{abstract}


Because there is much speculation of the relative stability, sensitivity, including solvent wetting of crystals, and performance of DADP and TATP, standard tests (i.e. DSC, drop weight impact, and SSED) were performed.

Keywords: Denature, Triacetone Triperoxide (TATP), Diacetone Diperoxide (DADP), SmallScale Explosivity Device (SSED), Drop-weight Impact Sensitivity 


\section{Introduction}

Triacetone triperoxide (3,3,6,6,9,9-hexamethyl-1,2,4,5,7,8-hexoxonane, TATP, CAS \#17088-37-8), is a sensitive, moderately powerful energetic material first reported in 1895 [1]. The one-pot synthesis from readily available precursors can, if certain precautions are met, produce TATP in high yield. TATP, being highly volatile (odor similar to pepper) and sensitive to friction and shock, does not lend itself to military or commercial applications; however, it has been used successfully by foreign and domestic terrorists. Properties of the pure material are reported in Table 1 along with standard military explosives for comparison. Literature procedures abound for TATP synthesis, from peer-reviewed journals and the internet, but all are similar [1, 4-6, 9-22]. Furthermore, an internet search provides a plethora of videos and forums of individuals who candidly show and speak about making TATP. Beginning in Israel in the 1980's, terrorist attacks have used TATP, either as the main or initiating charge [23]. Some of those incidents are shown in Table 2. Recent papers have investigated TATP synthesis, including unintended synthesis when acetone and hydrogen peroxide are used in cleaning procedures [30]. The focus of this study was to observe how varying reaction conditions affected yield of the reaction products TATP and diacetone diperoxide (DADP) and the extent to which the reaction is reversible or preventable (Scheme 1).

$<$ tabr1 >
$<$ tabr2>
<schr1> 


\section{Experimental Section}

\subsection{Reagents and Chemicals}

Acetone (HPLC-grade) and concentrated sulfuric acid (Certified ACS Plus) were obtained from Fisher Scientific. Hydrogen peroxide was obtained from Univar at 50\% w/w in water and was diluted to $30 \%$ and $9 \mathrm{wt} \%$ using distilled water. Higher concentrations of hydrogen peroxide were obtained by removal of water at elevated temperature. All concentrations of hydrogen peroxide were verified by refractometry to within $+/-1 \mathrm{wt} \%$ [31]. Adulterants (102 compounds) were obtained from Fisher Scientific and Sigma-Aldrich with varying degrees of purity.

\subsection{Preparation of Triacetone Triperoxide (TATP) with and without adulterants}

Into a glass test tube $(16 \mathrm{~mm} \times 150 \mathrm{~mm})$ containing a small stir bar, $1.53 \mathrm{~g}+/-0.01 \mathrm{~g}(13.5$ millimols, mmols) of 30wt\% hydrogen peroxide was weighed. The test tube was capped with Parafilm and placed in a temperature-controlled water bath. Acetone, $0.78 \mathrm{~g}+/-0.01 \mathrm{~g}$ (13.5mmols), neat or adulterated, was added to the hydrogen peroxide, and they were allowed to mix for a minimum of 15 minutes before sulfuric acid (40-96wt\%, generally, 1.35 to 0.135 mmols) was added. If higher concentration of HP were used, i.e. $\geq 50 \mathrm{wt} \%$, optimum results ( 100\% yield) was achieved using a 1:1:1 mole ratio of sulfuric acid (65wt\%): HP (50wt\%) : acetone and holding the mixture at $5^{\circ} \mathrm{C}$ for 24 hours.

The majority of the experiments were performed using a molar ratio of $0.01: 1$ or $0.10: 1$ of $46-50 \mathrm{wt} \%$ sulfuric acid to hydrogen peroxide. The 1 mol\% loading was achieved by using 1 drop, via pipet, of 40-50wt\% sulfuric acid. The $10 \mathrm{~mol} \%$ loading was achieved by using $0.276 \mathrm{~g}$ of $48 \mathrm{wt} \%$ sulfuric acid, delivered by pipette. The sulfuric acid concentration was verified by density. Acid addition was monitored for several reactions to determine temperature spike; a 
maximum of $8^{\circ} \mathrm{C}$ rise was seen in samples that were run at $25^{\circ} \mathrm{C}$. In one series of experiments, $90 \mathrm{wt} \%$ sulfuric acid was added, drop wise, in varying amounts to make step-wise increases in catalyst loading.

The solution was allowed to stir, behind a blast shield, for a minimum of 24 hours before filtration. The theoretical yield was 1.00 gram (4.5mmols) TATP; at this scale, multiple batches were run simultaneously. Following reactions for the specified lengths of time, test tubes were removed and filtered under water aspiration using $4.25 \mathrm{~cm}$ diameter Fisher P4 $(4-8 \mu \mathrm{m}$ particle retention) filter paper. Each reaction was washed with 75 to $150 \mathrm{~mL}$ distilled water at ambient temperature. Due to the high vapor pressure of TATP, the product was only allowed to dry only 15 minutes. If standing beads of water were removed by blotting, this length of time was sufficient to remove water without significant loss of TATP. Once mass of the solid product was obtained, each sample was placed into a glass vial with a plastic push-cap and placed into a $15^{\circ} \mathrm{C}$ freezer until analyses were performed. When analytically pure samples were required, the re-crystallization protocol cited below (Section 2.5) was employed. Melting point $94-96{ }^{\circ} \mathrm{C} ;{ }^{1} \mathrm{H}$ NMR $1.46 \mathrm{ppm}$ and ${ }^{13} \mathrm{C}$ NMR 21 and $107 \mathrm{ppm}\left(\mathrm{CDCl}_{3}\right)$; MS fragmentation pattern: $\mathrm{m} / \mathrm{z}=222$ (Parent, very small), $117\left[\left(\mathrm{CH}_{3}\right)_{2} \mathrm{CO}_{2} \mathrm{CCH}_{3} \mathrm{O}\right]^{+}$, (medium), $101\left[\left(\mathrm{CH}_{3}\right)_{2} \mathrm{CO}_{2} \mathrm{CH}_{3}\right]^{+}$(medium), $91\left[\left(\mathrm{CH}_{3}\right)\left(\mathrm{CH}_{2}\right) \mathrm{C}(\mathrm{OH})(\mathrm{OOH})\right]^{+}$(very small), $89\left[\mathrm{C}_{3} \mathrm{H}_{5} \mathrm{O}_{3}\right]^{+}$(very small), $75\left[\mathrm{C}_{3} \mathrm{H}_{7} \mathrm{O}_{3}\right]^{+}$(large), $73\left[\mathrm{C}_{2} \mathrm{H}_{5} \mathrm{O}_{2}\right]^{+}$(small), $59\left[\left(\mathrm{CH}_{3}\right)_{2} \mathrm{COH}\right]^{+}$(large), $58\left[\left(\mathrm{CH}_{3}\right)_{2} \mathrm{CO}\right]^{+}$(large), $43\left[\mathrm{CH}_{3} \mathrm{CO}\right]^{+}$ (dominant), $29\left[\mathrm{CH}_{3} \mathrm{CH}_{2}\right]^{+}$(medium), $15\left[\mathrm{CH}_{3}\right]^{+}$(medium).

\subsection{Sample Preparation of Diacetone Diperoxide (DADP)}

Similar to the TATP synthesis reactions, $13.5 \mathrm{mmols}$ of hydrogen peroxide was combined with $13.5 \mathrm{mmols}$ of acetone in a test tube in a temperature controlled bath. The hydrogen peroxide concentration varied from $30 \mathrm{wt} \%$ to $65 \mathrm{wt} \%$; two concentrations of sulfuric acid, 
$55 \mathrm{wt} \%$ and $63 \mathrm{wt} \%$, were used. The molar ratio of sulfuric acid to hydrogen peroxide was varied from $0.3: 1$ to $1.5: 1$ for $65 \mathrm{wt} \% \mathrm{HP}$; $0.55: 1$ to $1.8: 1$ for $50 \%$ wt HP; and $1: 1$ to $2.5: 1$ for $30 \mathrm{wt} \%$ HP. Reactions were run at $25^{\circ} \mathrm{C}$ and $5^{\circ} \mathrm{C}$ for 24 hours. Reactions were cooled in an ice bath while acid was added before being transferred to the $25^{\circ} \mathrm{C}$ bath; reactions at $5^{\circ} \mathrm{C}$ were not cooled further prior to acid addition. Filtration procedures were similar to that for TATP syntheses (Section 2.2), but more water ( $>200 \mathrm{~mL}$ ) was used to rinse precipitate since more acid was used in DADP preparation. When high sample purity was required, the re-crystallization protocol cited below (Section 2.5) was employed. Melting point 131-133 ${ }^{\circ} \mathrm{C} ;{ }^{1} \mathrm{H}$ NMR 1.35 and $1.80 \mathrm{ppm}$ and ${ }^{13} \mathrm{C}$ NMR 20, 22 and $108 \mathrm{ppm}\left(\mathrm{CDCl}_{3}\right)$; MS fragmentation pattern: $\mathrm{m} / \mathrm{z}=133$ $\left[\left(\mathrm{CH}_{3}\right)_{2} \mathrm{OCO}_{2} \mathrm{C}\left(\mathrm{CH}_{3}\right) \mathrm{O}\right]^{+}$(small), $117\left[\left(\mathrm{CH}_{3}\right)_{2} \mathrm{CO}_{2} \mathrm{CCH}_{3} \mathrm{O}\right]^{+}$(small), $101\left[\left(\mathrm{CH}_{3}\right)_{2} \mathrm{CO}_{2} \mathrm{CH}_{3}\right]^{+}$ (large), $89\left[\mathrm{C}_{3} \mathrm{H}_{5} \mathrm{O}_{3}\right]^{+}$(very small), $75\left[\mathrm{C}_{3} \mathrm{H}_{7} \mathrm{O}_{3}\right]^{+}$(small), $73\left[\mathrm{C}_{2} \mathrm{H}_{5} \mathrm{O}_{2}\right]^{+}$(small), 59 $\left[\left(\mathrm{CH}_{3}\right)_{2} \mathrm{COH}\right]^{+}$(large), $58\left[\left(\mathrm{CH}_{3}\right)_{2} \mathrm{CO}\right]^{+}$(large), $43\left[\mathrm{CH}_{3} \mathrm{CO}\right]^{+}$(dominant), $29\left[\mathrm{CH}_{3} \mathrm{CH}_{2}\right]^{+}$ (medium), $15\left[\mathrm{CH}_{3}\right]^{+}$(medium).

\subsection{Preparation of TATP/DADP Mixtures}

Mixtures of TATP and DADP were prepared by dissolving proportional masses of each into $25 \mathrm{~g}$ acetone, e.g. $75 / 25,50 / 50$ and 25/75, with a total mass between $1.50-2.00$ g. The acetone solution was poured onto $100 \mathrm{~g}$ of distilled water with vigorous stirring. After 10-15 minutes of stirring, the mixture was filtered and washed with room temperature distilled water; organic solvents were not used as a wash due to differing solubilities of DADP and TATP. The solid was allowed to dry for 30 minutes before being weighed and placed into a glass vial with plastic push-cap. 


\subsection{Recycling of Samples}

Samples of TATP and DADP no longer needed were recrystallized. Double recrystallization was used to prepare TATP for standards. The first recrystallization was from methanol, and the solution was allowed to cool slowly to room temperature before being placed into a freezer. After filtering and washing with cold $\left(-15^{\circ} \mathrm{C}\right)$ methanol, the TATP was redissolved in pentane. The pentane solution was cooled rapidly in an ice water and salt bath with continued stirring. In this manner, a smaller particle size was obtained. Recrystallization of DADP was performed in methanol or ethyl acetate.

\subsection{Adulterated TATP}

Adulterated solutions of acetone were prepared by adding acetone to the desired mass of adulterant in a $15 \mathrm{~mL}$ vial with a total mass of $10 \mathrm{~g}$. Over 100 adulterants were tested in a range of concentrations from $1 \mathrm{wt} \%$ to $50 \mathrm{wt} \%$. Sparingly soluble adulterants were used as saturated solutions; for these adulterants, saturation was below 10wt\%. In these cases, rather than determine solubility and adjust the mass of acetone solution to maintain a ratio of 1:1 between hydrogen peroxide and acetone, the standard mass of acetone, 0.78g, was used. For these solutions, the actual mass ratio of hydrogen peroxide to acetone fell between 1:1 and 1.12:1. Reactions using adulterated acetone were run in duplicate per concentration and specific reaction conditions; few were run only once. Reaction times were measured from the time of addition of acid to filtration of the solid precipitate. 


\subsection{Analytical Methods}

Melting points were obtained on a Mel-Temp model 1001, without temperature corrections; samples containing DADP required sealing both ends of the capillary tubes to prevent sublimation. For multiple samples produced under the same conditions, the melting point range reported is an average of the onset of melting and completion of melting (i.e. low end of the range and the high end of the range) observed for all the samples.

Gas chromatograph (Agilent 6890) coupled to either a mass selective detector (Agilent 5793) (GC/MS) or a micro-electron capture detector (GC/ $\mu$ ECD) was used to quantify TATP and DADP against pure samples in acetonitrile solutions. Most impurities present in samples could not be positively identified by GC/MS, nor were laborious attempts made to do so. Samples for GC analysis were prepared by weighing 9-11mg of sample into a $10 \mathrm{~mL}$ volumetric flask and filling to mark with acetonitrile; for GC/ $\mu$ ECD analysis, a further 1:10 dilution was performed.

The GC/MS inlet temperature was $150^{\circ} \mathrm{C}$ and a flow of $11.6 \mathrm{~mL} / \mathrm{min}$ (helium carrier gas). The inlet was operated in split mode, with a ratio of 5:1 and a split flow of $7.5 \mathrm{~mL} / \mathrm{min}$. A $10 \mathrm{~m}$ DB5-MS column (J\&W) with a $0.25 \mathrm{~mm}$ inner diameter and a $0.25 \mu \mathrm{m}$ film thickness was operated under a constant flow condition of $1.5 \mathrm{~mL} / \mathrm{min}$. The oven program had an initial temperature of $50^{\circ} \mathrm{C}$ with a $4 \mathrm{~min}$ hold followed by a $10^{\circ} \mathrm{C} / \mathrm{min}$ ramp to $200^{\circ} \mathrm{C}$ and a post-run at $310^{\circ} \mathrm{C}$ for $1 \mathrm{~min}$. The transfer line temperature was $250^{\circ} \mathrm{C}$ and the mass selective detector source and quadrupole temperatures were $230^{\circ} \mathrm{C}$ and $150^{\circ} \mathrm{C}$, respectively, and electron-impact ionization was used.

The GC/ $\mu \mathrm{ECD}$ inlet temperature was $170^{\circ} \mathrm{C}$, a pressure of 2.36psi (helium carrier gas) and operated in splitless mode. The 6m RTX-TNT2 column (Restek, 0.53mm inner diameter, 
$1.5 \mu \mathrm{m}$ film thickness) was held to constant pressure. The oven program had an initial temperature of $40^{\circ} \mathrm{C}$ and a $2 \mathrm{~min}$ hold followed by a $20^{\circ} \mathrm{C} / \mathrm{min}$ ramp to $150^{\circ} \mathrm{C}$, a $1 \mathrm{~min}$ hold and a post-run at $250^{\circ} \mathrm{C}$ for 2 mins. The detector was set to $280^{\circ} \mathrm{C}$ with $30 \mathrm{~mL} / \mathrm{min}$ nitrogen makeup gas flow.

Physical attributes, including density, impact sensitivity, explosivity, and thermal stability, were characterized for pure TATP and DADP and mixtures of TATP/DADP, following determination of approximate ratios of TATP to DADP using GC/ $\mu$ ECD. Crystal densities were obtained on a Micromeritics Helium Pycnometer with barium chloride calibration. A single sample was analyzed ten times by the instrument and a density given with a standard deviation. Due to the high vapor pressure of DADP, an accurate density was not obtained for mixtures of TATP and DADP or neat DADP. Impact sensitivity, i.e. drop-weight impact, was performed using an apparatus modeled after Lawrence Livermore National Laboratories drop weight impact machine; the weight used was $1.91 \mathrm{~kg}$ [32]. A small-scale explosivity device (SSED) was used, wherein a mass of material is placed inside a British 0.303 rifle cartridge (primer removed) and detonated with a Teledyne RISI RP-3 (29mg PETN) detonator. Typically the mass of material used was 2.0000g, unfortunately, due to the low tap density and inability to pack TATP or DADP into the cartridge, the mass was significantly less. Relative power output is correlated by finding the percentage of the base remaining versus the initial mass of the cartridge [33, 34].

A TA Instruments Q100 differential scanning calorimeter (DSC) was used to determine onset temperature of decomposition, heat release and exothermic maximum temperature. Calibration of the DSC consisted of sapphire disc $\mathrm{T}_{\text {zero }}$ calibration followed by 4 metal standards for heat release and temperature calibration: indium, tin, lead and zinc. Samples were sealed in glass capillary tubes using $0.1-0.2 \mathrm{mg}$ of material. Standard run conditions were: Equilibrate at - 
$10^{\circ} \mathrm{C}$, ramp $20^{\circ} \mathrm{C} / \mathrm{min}$ to $30^{\circ} \mathrm{C}$, turn data storage on, ramp $20^{\circ} \mathrm{C} / \mathrm{min}$ to $400^{\circ} \mathrm{C}$. For mixtures of TATP and DADP, the DSC was used for observing eutectic and non-eutectic melting.

In adulteration experiments, percent yield of white precipitate formed was the main metric for determining if adulterants affected the reaction between hydrogen peroxide and acetone. Neat reactions were run using similar reaction times, temperature and catalyst loading for comparison. Percent yields were calculated based on either hydrogen peroxide or acetone, whichever was the limiting reagent; the ratio between hydrogen peroxide and acetone was 1:1 for the majority of the reactions. Purity/identity of the white precipitate was judged primarily by melting point, but in some cases GC/MS or GC/ $\mu$ ECD analysis was performed. While GC/MS could not reveal inorganic salts or solvents which might decrease melting point, it would reveal organic impurities. Use of TATP calibration standards allowed determination of whether the solid was primarily TATP or whether a large percentage of its mass was some material invisible to the GC detector. Hence, in several cases we report a decrease in melting point but a high level of purity indicated by GC/MS or GC/ $\mu E C D$ analysis.

\section{Results and Discussion}

\subsection{Factors Affecting TATP Yield}

\subsubsection{Hydrogen Peroxide to Acetone Ratio}

An optimum molar ratio of hydrogen peroxide (HP) to acetone was determined using two different means of varying the ratio: the amount of HP was held constant at $13.5 \mathrm{mmols}$ and the amount of acetone was varied, or the amount of acetone was held constant at $13.5 \mathrm{mmols}$ and the amount of HP was varied. The HP-to-acetone molar ratio was varied between 0.25:1 to 4:1 with two different sulfuric acid (48wt\%) amounts, $0.14 \mathrm{mmols}(1 \mathrm{~mol} \%)$ or $1.35 \mathrm{mmols}$ (10mol\%) 
(Figure 1). Regardless of which reagent was held constant, a molar ratio between 0.5:1 and 2:1 resulted in good yield of TATP; outside this range, the yield decreased.

$<$ figr1 $>$

\subsubsection{Concentration of HP and Reaction Length}

Yield of TATP increased with increasing concentration of HP even though the molar ratios of $\mathrm{HP}$ to acetone of $1: 1$ and sulfuric acid (48wt\%) to HP of $0.01: 1$ were held constant (Figure 2). In a 48 hour reaction, 84wt\% HP yielded 84wt\% TATP, while 30wt\% HP yielded 30\% TATP. At low amounts of acid (1mol\%), an increase in reaction length increased yield; with 30wt\% HP, the yield more than doubled between 24 hours (16\%) and 72 hours (35\%) (Figure 2).

$<$ figr2 $>$

$<$ figr3 $>$

\subsubsection{Reaction Temperature}

The temperature of the reaction was varied from $5^{\circ} \mathrm{C}$ to $40^{\circ} \mathrm{C}$. While concentrations of sulfuric acid (48wt\%) and HP (30wt\%) were not varied, their molar ratio was (Figure 3). At temperatures less than $25^{\circ} \mathrm{C}$, molar ratios of acid to $\mathrm{HP}$ higher than $0.1: 1$ increased yield; above $25^{\circ} \mathrm{C}$, increasing the molar ratio of acid to HP above $0.1: 1$ resulted in decreased yield of solid peroxide. With 0.1:1 acid to HP molar ratio, a maximum yield was obtained at $25^{\circ} \mathrm{C}$. By $\mathrm{GC} / \mu \mathrm{ECD}$ analysis, the reactions ran at $40^{\circ} \mathrm{C}$ with a molar ratio of acid to HP of $0.2: 1$ yielded 13wt\% DADP; all other reactions yielded TATP only.

\subsubsection{Acid to HP/Acetone Ratio}


Two reaction temperatures, $5^{\circ} \mathrm{C}$ and $25^{\circ} \mathrm{C}$, were used to observe product distribution over a wide range of concentrations and amounts of sulfuric acid (48wt\%-96wt\%) and HP (30wt\% 84wt\%); molar ratios ranged from $0.002: 1$ to 2.5:1 (Figure 4). HP to acetone molar ratio was set as 1:1 and was not varied. At $5^{\circ} \mathrm{C}$, an increase in yield was observed with increased acid amount, reaching nearly $100 \%$ at an acid to $\mathrm{HP}$ molar ratio of $0.8: 1$, before declining. At $25^{\circ} \mathrm{C}$, overall yield reached a maximum at an acid to HP molar ratio of 0.4:1 before declining. Above a molar ratio of acid to $\mathrm{HP}$ of $0.5: 1$, reactions ran at $5^{\circ} \mathrm{C}$ had greater overall yields than identical reactions ran at $25^{\circ} \mathrm{C}$. Presumably, at higher temperatures, the use of larger amounts of acid resulted in decomposition of the peroxides. Figure 4 is expressed as total yield because analysis was of total precipitate formed, both TATP and DADP.

$<$ figr4 $>$

\subsection{Conditions Affecting DADP Formation}

In order to assign percentages of TATP and DADP of the overall mixtures (shown in

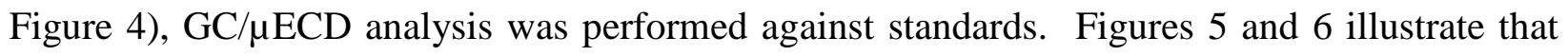
high temperature $\left(25^{\circ} \mathrm{C}\right.$ vs. $\left.5^{\circ} \mathrm{C}\right)$ and high acid content favored DADP formation. Temperature affected overall yield (Figure 4) and product distribution; for example, under the same conditions, 1:1 molar ratio of sulfuric acid (63wt\%) to HP (65wt\%), samples ran at $5^{\circ} \mathrm{C}$ yielded over $80 \%$ TATP, while samples ran at $25^{\circ} \mathrm{C}$ were almost $100 \%$ DADP.

$<$ figr5 $>$

$<$ figr6 $>$

Both Hernandez and Matyas discussed some aspects of the TATP/DADP conversion. Hernandez reported that the reaction of acetone and hydrogen peroxide at temperatures below $0^{\circ} \mathrm{C}$ gave exclusively TATP, but at $20^{\circ} \mathrm{C}$ a mixture of TATP and DADP was obtained (amount 
of acid was not reported) [17]. Matyas noted a dependence on acid concentration. He found that when an acetone and hydrogen peroxide (30wt\%) mixture was treated with 1 molar equivalent of 96wt\% sulfuric acid, DADP formed; when 65wt\% sulfuric acid was used, 2.5 molar equivalents of acid were necessary to form DADP [15].

In the present experiments, the concentration of hydrogen peroxide was found to dictate the amount of acid necessary to convert TATP to DADP. As the initial concentration of HP was increased (concentration of sulfuric acid held constant), the amount of acid necessary for complete conversion of TATP to DADP decreased. For example, with 30wt\% HP and 63wt\% sulfuric acid, a 1.5:1 acid to HP mol ratio yielded only DADP; when the initial concentration of HP was increased to $65 \mathrm{wt} \%$, a smaller molar ratio, 0.8:1, induced complete conversion to DADP (Figure 7). Raw data collected at $5^{\circ} \mathrm{C}$ and $25^{\circ} \mathrm{C}$ is provided in supplemental data.

$<$ figr7>

While the importance of acidity on the HP/acetone reaction has long been acknowledged, it appears the volume of water in reaction mixture plays an important role. Since both HP and acid were aqueous, the relative ratios of reactants were complex. Figure 8 illustrate that waterto-sulfuric acid molar ratio alone is insufficient to determine the resultant product mix. As the total volume of the reaction mixture decreased with increasing HP concentration, the volume occupied by the precipitated solid peroxide remained nearly constant. The result was that less TATP transformed into DADP at conditions where similar water-to-sulfuric-acid molar ratios achieved by high acid concentration and low HP concentration yielded strictly DADP. Figure 9 plots the reaction products at $25^{\circ} \mathrm{C}$ as a function of HP moles per $\mathrm{kg}$ of water and sulfuric acid moles per kg of water, where water comes into the reaction with both the HP and the acid. This allows select synthesis of TATP or DADP. If the desired product is TATP then high 
concentration of HP and low acid must be used (black diamonds, Figure 9); for high yield of DADP, lower concentration of HP and higher concentration acid are required (black circles, Figure 9).

$<$ figr8 $>$

$<$ figr9>

\subsection{Physical Properties}

\subsubsection{TATP/DADP Mixture}

On do-it-yourself synthesis web sites there is often speculation on the effect of forming DADP rather than TATP in improvised syntheses. The concern is which peroxide is more sensitive or unstable. The fact that TATP exhibits a lower DSC exotherm $\left(239^{\circ} \mathrm{C}\right)$ than DADP $\left(251^{\circ} \mathrm{C}\right.$ ) indicates it is somewhat less thermally stable (Table 3). The DSC thermograms indicated that a low melting eutectic was formed when a small amount of DADP contaminated TATP. Analysis of crude samples showed significant destabilization if quantities of acid exceeded $10 \mathrm{~mol} \%$ or impurities were present caused from adulteration of the acetone with 20wt\% 2-butanone or 2-pentanone (Table 3). Mixtures of TATP and DADP were found to be more impact sensitive than either pure chemical. Impact sensitivity was only slightly decreased for crude samples (Table 4). Also in Table 4 are the results of the Small Scale Explosivity Device (SSED) tests; which measures the explosive power of 2 gram samples initiated with small detonators. Both TATP and DADP perform poorer than TNT, leaving $42 \%$ of the cartridge case attached to the base, but this result was achieved with considerably less TATP ( 0.8g) than DADP ( 1.3g).

$<$ tabr3>

$<$ tabr4> 


\subsubsection{Wetted TATP}

While do-it-yourself “chemists” speculate on the effect of DADP contamination of their TATP, explosive disposal personnel speculate on methods to “desensitize” TATP sufficiently so that it can be safely moved from a domestic location. To illustrate the potential associated hazards, a $4.3 \mathrm{~kg}$ weight was used in the impact device against 20mg TATP. Pure TATP produced a "go" response at a drop height of 5cm. Wetting it with ethanol (EtOH), a 50/50 mixture of ethanol/water or diesel resulted in a mixture that usually did not "go" even when the weight was raised to $100 \mathrm{~cm}$ (Table 5). A popular remedy, WD-40, did not show reproducible desensitization, and water, alone, showed none. We attribute the "desensitizing” effect of certain liquids and the failure of others to their relative tendency to dissolve TATP. Even though the amount of ethanol was too little to dissolve the TATP and the material did not appear to be dissolving, we believe the outer coating was sufficiently softened to reduce sensitivity to impact. Water, in which TATP has little solubility, did not reduce its sensitivity to impact. $<\operatorname{tabr5}>$

When the entire test series was repeated with a different batch of TATP; less favorable results were obtained (Table 5). Mixtures which showed reduced sensitivity, e.g. EOH/water, now produced a "go". Particle size distinctions (i.e. fine versus coarse) were based on visual observations. This suggested that morphology of different batches might influence sensitivity. Factors such as particle size, factors which influence aggregation and product purity can be influenced by subtle details associated with synthesis such and temperature, solvent composition and ionic strength. Factors facilitating aggregation would likely increase sensitivity of TATP to shock and friction.

\subsection{Adulterated Reactions}


To inhibit the reaction between acetone and hydrogen peroxide we sought chemicals to adulterate the precursors without interfering with their desired usage. The ideal adulterant would be kept at a few percent loading, be relatively non-toxic and completely inhibit formation of TATP under most conditions. Our approach was to seek out additives that destroyed hydrogen peroxide, diverted hydrogen peroxide (by reacting with it), quenched the acid catalyst, or made isolation of TATP cumbersome. Over one hundred adulterants, chosen from eight classes of reagents were tested: (1) antioxidants; (2) radical initiators; (3) metal salts; (4) molecules containing reactive bonds; (5) ketones other than acetone; (6) organic solvents to prevent TATP precipitation; (7) amines and inorganic bases; (8) halides and halogenated organics. Reactions involving adulterated solutions of acetone used a molar ratio of 1:1 hydrogen peroxide (30wt\%) to acetone and either 1) $25^{\circ} \mathrm{C}$ with $1 \mathrm{~mol} \%$ sulfuric acid for 48 hours or 2) $5^{\circ} \mathrm{C}$ with $10 \mathrm{~mol} \%$ sulfuric acid for 24 hours. DADP was not observed by GC/MS or GC/ $\mu$ ECD for any of these reactions. Most of the adulterants failed to retard TATP formation. Adulterants and rational for choosing them is as follows:

(1) Antioxidants were added in an attempt to quench hydroxyl and hydroperoxy radicals should they be formed during synthesis of TATP. However, butylated hydroxytoluene, vanillic acid, butylated hydroxyanisole, diethyl phthalate, benzoquinone, tannic acid, pyrogallol, 4hydroxyphenylacetic acid, resorcinol, p-hydroxyphenylacetic acid, gallic acid, butylated hydroxytoluene, vitamin E, dioctyl phthalate, and pyrogallol failed to reduce TATP production even when they were present in up to $30 \mathrm{wt} \%$ concentration.

(2) Radical initiators (t-butyl peroxide, benzoyl peroxide, sodium persulfate, sodium bisulfite, ammonium bisulfite, glycol sulfite, acetone sodium bisulfate) were added in an attempt to destroy hydrogen peroxide before it reacted with acetone. None were successful. 
(3) Catalytic decomposition of hydrogen peroxide and TATP can be achieved by some metal salts; however, copper salts of nitrate, sulfate, acetate, and iodide; iron salts of acetylacetonate, phosphate, chloride, phthalocyanine, and ferrocene; tin chloride; and zinc sulfate and chloride did not reduce TATP formation, while cooper chloride and bromide did.

(4) Molecules containing reactive bonds were added to offer hydrogen peroxide an alternative site for reaction. Terephthalaldehyde, benzaldehyde, furfural, formaldehyde, ethyl propiolate, 2pentyn-1-ol, propargyl alcohol, methyl methacrylate, styrene, 5-vinyl-2-norbornene methacrylic acid, isoprene, t, t-1,4-diphenyl-1,3-butadiene, isobutylene, 7,7,8,8-tetracyanoquino-dimethane failed to effectively compete with acetone when added at the $20 \mathrm{wt} \%$ level. Only at $40 \mathrm{wt} \%$ to $50 \mathrm{wt} \%$ did these adulterants become effective.

(5) To compete with acetone for oxidation formamide, cyclohexanone, cyclopentanone, 2- and 3-pentanone, 2-butanone, 2,3- and 2,4-butanedione, benzil, 1,4-cyclohexanedione, and 2nonanone were added. At $20 \mathrm{wt} \%$ they were slightly effective; to eliminate TATP formation they needed to be present at $50 \mathrm{wt} \%$.

(6) Organic solvents (methanol, carbitol, ethylene glycol, diethyl ether, ethyl acetate, toluene, and t-butanol) added to acetone at up to $50 \mathrm{wt} \%$ did not prevent precipitation of TATP from solution.

(7) Amines and other bases ammonium or potassium hydroxide, trimethyl- or triethyl-amine, aniline, diaminopropane, diethylamine, diethylene triamine, ethylenediamine, hydrazine monohydrate, phenyl hydrazine, diethyl- or diisopropyl-amine, piperidine, or pyridine neutralized the acid catalyst [35]. They were effective at the $1 \mathrm{wt} \%$ level in preventing TATP formation. However, their effect was readily overcome by the addition of excess acid. 
Furthermore, many amines are toxic and on a time-scale of months, react with acetone, even when kept cold $\left(-15^{\circ} \mathrm{C}\right)$.

Two type of adulterants were effective at reducing TATP formation-bases and iodide species. Iodide is known to decompose hydrogen peroxide (Eq. 1) with iodide consumed at a molar ratio of 3:1 ( $\left.\mathrm{I}^{-}: \mathrm{HP}\right)$; bromide was known to react similarly [36,37]. Therefore, halide salts [ammonium iodide $\left(\mathrm{NH}_{4} \mathrm{I}\right), \quad$ tetrabutylammonium iodide $\quad$ (TBAI), methyltriphenylphosphonium iodide (MTPPI), potassium iodide (KI) and tetrabutylphosphonium bromide (TBPBr)] and organic halides [diatrizoic acid $\left(\mathrm{C}_{11} \mathrm{H}_{9} \mathrm{~N}_{2} \mathrm{O}_{4} \mathrm{I}_{3}\right)$, and Nbromosuccinimide (NBS)] were used. Due to the high formula weight of iodine compounds, the molar ratio was low. For example, with a $10 \mathrm{wt} \% \mathrm{NH}_{4} \mathrm{I}$ solution, the molar ratio of $\mathrm{I}^{-}$: HP was 1:29; however, this was sufficient to disrupt the formation of TATP. Similar to amine adulterants, use of increased acid catalyst could overcome the inhibitory effect of iodide on TATP production. Furthermore, acetone solutions containing iodide salts, especially $\mathrm{NH}_{4} \mathrm{I}$, darken after a few months storage, but the inhibiting effect of iodide was not diminished.

\section{Conclusion}

The reaction between hydrogen peroxide and acetone was investigated to identify conditions that affect yield and purity of TATP and/or DADP. The molar ratio of HP to acetone was able to be varied between $0.5: 1$ and 2:1 without yield being drastically affected. Reaction temperature, reactant ratios to each other, and initial reactant concentrations affected overall yield as well as the ratio of TATP to DADP produced. Analysis of reaction conditions was complicated by the fact that both HP and sulfuric acid were aqueous. Some volume of solution was required for TATP conversion to DADP. Figure 9 outlines reaction conditions to be selected toward the desired product. Adulterating acetone to inhibit TATP formation was difficult to 
achieve at low levels of adulterant. Some materials - amines, iodide salts, ketones, and metal salts - showed promise, but either their toxicity or their adverse effect on solution stability would be hindrances to their use, e.g. amines, iodide and metal salts. Low molecular weight ketones, i.e. methyl ethyl ketone and 2-pentanone at relatively high adulterant concentration ( $\geq 20 \mathrm{wt} \%)$ proved most effective, with no loss in stability and minimal increase in toxicity.

\section{References}

[1] R. Wolffenstein, Action of Hydrogen Peroxide on Acetone and Mesityl Oxide, Ber. Deut. Chem. Ges., 1895, 28, 2265-9.

[2] V. Egorshev, V. Sinditskii, S. Smirnov, E. Glinkovsky and V. Kuzmin, A Comparative Study on Cyclic Acetone Peroxides, Proceedings of the $12^{\text {th }}$ Seminar on New Trends in Research on Energetic Materials, 2009, 115-125, Pardubice, Czech Republic.

[3] R. Meyer, J. Kohler and A. Homburg, Explosives, Sixth, Completely Revised Edition, Wiley-VCH Verlag GmbH, Weinheim, 2007, p. 251 \& 343.

[4] R. Matyas, Influence of Oil on Sensitivity and Thermal Stability of Triacetone Triperoxide and Hexamethylenetriperoxide diamine, Proc. of the $8^{\text {th }}$ Seminar on New Trends in Research on Energetic Materials, 2005, 687-692, Pardubice, Czech Republic.

[5] R. Matyas, J. Selesovsky, Power of TATP Based Explosives, J. Haz. Mat., 2009, 165, 9599.

[6] J. C. Oxley, J. L. Smith, K. Shinde, J. Moran, Determination of the Vapor Density of Triacetone Triperoxide (TATP) Using a Gas Chromatography Headspace Technique, Propellants, Explos., Pyrotech., 2005, 30, 127-130.

[7] J. C. Oxley, J. L. Smith, W. Luo, J. Brady, Determining the Vapor Pressures of Diacetone Diperoxide (DADP), and Hexamethylene Triperoxide Diamine (HMTD), Propellants, Explos., Pyrotech, 2009, 34, 539-543.

[8] R. B. Cundall, T. F. Palmer, C. E. C. Wood, Vapour Pressure Measurements on Some Organic High Explosives, J. Chem. Soc. Faraday Trans., 1978, 74(6), 1339-1345.

[9] M. Costantini, Destruction of Acetone Peroxides, US Patent 5003109 1991, Rhone-Poulenc Chimie, Courbevoie, France.

[10] F. Dubnikova, R. Kosloff, J. Almog, Y. Zeiri, R. Boese, H Itzhaky, A. Alt, E. Keinan, Decomposition of Triacetone Triperoxide is an Entropic Explosion, J. Am. Chem. Soc. 2005, 127, 1146-1159. 
[11] L. Jensen, P.M. Mortensen, R. Trane, P. Harris, R. W. Berg, Reaction Kinetics of Acetone Peroxide Formation and Structure Investigations Using Raman Spectroscopy and X-Ray Diffraction, Appl. Spectrosc., 2009, 63(1), 92-97.

[12] H. Jiang, G. Chu, H. Gong, Q. D. Qiao, Tin Chloride Catalyzed Oxidation of Acetone with Hydrogen Peroxide to Tetrameric Acetone Peroxide, J. Chem. Res., 1999, 4, 288-289.

[13] C. M. Mateo, G. N. Eyler, E. E. Alvarez, A. I. Canizo, New Method for the Synthesis of Cyclic Acetone Triperoxide, Informacion Tecnologica, 1998, 9(2), 19-22.

[14] R. Matyas, J. Pachman, Thermal Stability of Triacetone Triperoxide, Sci. Technol. Ener. Mat., 2007, 68, 111-116.

[15] R. Matyas, J. Pachman, Study of TATP: Influence of Reaction Conditions on Product Composition, Propellants, Explos., Pyrotech., 2010, 35, 31-37.

[16] N. A. Milas, A. Golubovic, Studies in Organic Peroxides. XXVI. Organic Peroxides derived from Acetone and Hydrogen Peroxide, J. Am. Chem. Soc. 1959, 81, 6461-6462.

[17] L. C. Pacheco-Londono, A.J. Pena, O.M. Primera-Pedrozo, S.P. Hernandez-Rivera, N. Mina, R. Garcia, R.T. Chamberlain, R.T. Lareau, An Experimental and Theoretical Study of the Synthesis and Vibrational Spectroscopy of Triacetone Triperoxide (TATP), Proceedings of SPIE-The Int'l. Soc. Optical Engineering, 403 (Pt. 1: Sensors and Command, Control, Communications, and Intelligence (C31) Technologies for Homeland Security and Homeland Defense III), 2004, 279-287, Orlando, FL, USA.

[18] O. Reany, M. Kapon, M. Botoshansky, E. Keinan, Rich Polymorphism in TriacetoneTriperoxide, Cryst. Growth Des., 2009, 9, 3661-3670.

[19] S. Zeman, W. A. Trzcinski, R. Matyas, Some Properties of Explosive Mixtures Containing Peroxides Part I: Relative Performance and Detonation of Mixtures with Triacetone Triperoxide, J. Haz. Mat., 2008, 154, 192-198.

[20] http://www.totse.info/en/ - accessed June 20, 2011

[21] http://www.shadowrx.com/forums/showthread.php?t=931 - accessed June 20, 2011

[22] http://www.roguesci.org/chemlab/energetics/acetone_peroxide.html-accessedJune 20, 2011

[23] H. Schubert, A. Kuznetsov, Detection of liquid explosives and flammable agents in connection with terrorism, Springer, The Netherlands, 2008, p. 36.

[24] http://articles.cnn.com/2002-01-07/us/reid.timeline_1_flight-crew-american-airlines-flightbrixton-mosque?_s=PM:US, accessed June 20, 2011. 
[25] www.justice.gov/opa/documents/zazi-detention-memo.pdf, accessed June 20, 2011

[26] http://p10.hostingprod.com/@spyblog.org.uk/blog/2007/01/16/july-21st-2005-londonbomb-attack-trial-hydrogen-peroxide-chapati-flour-tatp-det.html, accessed June 20, 2011

[27] http://www.bbc.co.uk/news/world-europe-11345887, accessed June 20, 2011

[28] http://www.masslive.com/localbuzz/index.ssf/2009/06/actionreaction_how_one_teens_c.ht $\mathrm{ml}$, accessed June 20, 2011

[29] http://homelandsecurityus.com/archives/1386, accessed June 20, 2011.

[30] J. C. Oxley, J. Brady, S. A. Wilson, J. L. Smith, The Risk of Mixing Dilute Hydrogen Peroxide and Acetone Solutions, J. Chem. Health Safety, 2011, in press.

[31] W. C. Schumb, C. N. Satterfield, R. L. Wentworth, Hydrogen Peroxide, Reinhold Publishing Corp, New York, 1955, p. 269-270, 337-338, 467-500.

[32] L. R. Simpson, M. F. Foltz, LLNL Small-Scale Drop-Hammer Impact Sensitivity Test, Report UCRL-ID-119665, 1995, Lawrence Livermore National Lab, Livermore, CA.

[33] J.C. Oxley, J.L. Smith, E. Rogers, M.A. Hamad, E. Resende, Small Scale Explosivity Testing, J. Ener. Mat., 1999, 17(4), 331-343.

[34] J.C. Oxley, J.L. Smith, E. Resende, Determining Explosivity Part II: Comparison of SmalScale Cartridge Test to Actual Pipe Bombs, J. For. Sci., 2001, 46(5), 1070-1075.

[35] E.G.E. Hawkins, Reactions of Organic Peroxides. Part XII. Amino-peroxides from Acyclic Carbonyl Compounds, J. Chem. Soc (C), 1969, 19, 2678-81.

[36] H. A. Liebhafsky, A. Mohammed, The Kinetics of the Reduction, in Acid Solution, of Hydrogen Peroxide by Iodide Ion, J. Am. Chem. Soc., 1933, 55 (10), 3977-3986.

[37] W. C. Bray, R. S. Livingston, The Catalytic Decomposition of Hydrogen Peroxide in the Bromine-Bromide Solution, and a Study of the Steady State, J. Am. Chem. Soc., 1923, 45 (5), 1251-1271.

\section{Acknowledgements}

The authors wish to thank the Department of Homeland Security for funding via Cooperative agreement \# 2008-ST-061-ED000 through the University Programs Center of Excellence as well as through the Science \& Technology Division. 
Table 1. TATP Characteristics

\begin{tabular}{|c|c|c|c|c|c|}
\hline & \multicolumn{2}{|c|}{ Sensitivity } & \multicolumn{2}{|c|}{ Power } & \multirow{2}{*}{$\begin{array}{c}\text { Vap. Pr. } \\
\text { at } 25^{\circ} \mathrm{C} \\
\text { (torr) }\end{array}$} \\
\hline & Impact (J) & $\begin{array}{c}\text { Friction } \\
(\mathrm{N})\end{array}$ & Trauzl & $\begin{array}{c}\text { Ballistic } \\
\text { Mortar }\end{array}$ & \\
\hline \multirow{2}{*}{ TATP } & 0.2 [2], 0.3 [3], & 0.1 [3], & \multirow{2}{*}{$80 \%$ [3] } & \multirow{2}{*}{$62 \%$ [5] } & \multirow{2}{*}{$\begin{array}{l}5 \times 10^{-2} \\
{[6]}\end{array}$} \\
\hline & $0.8[4], 1.0^{\mathrm{a}}$ & $0.015[4]$ & & & \\
\hline DADP & $0.4[2], 2.3^{\mathrm{a}}$ & -- & -- & -- & $\begin{array}{l}1.3 \times 10^{-1} \\
{[7]}\end{array}$ \\
\hline PETN & $3[3], 6^{\mathrm{a}}$ & 60 [3] & -- & -- & -- \\
\hline TNT & -- & -- & $100 \%$ & $100 \%$ & $\begin{array}{l}5.8 \times 10^{-6} \\
{[8]}\end{array}$ \\
\hline
\end{tabular}

\section{a This Work}

Table 2. Terrorist Use of Peroxide Explosives

\begin{tabular}{|c|c|c|c|c|}
\hline Where: & Who: & What: & When: & Ref: \\
\hline Flight to US & Reid & $\begin{array}{l}\text { TATP initiator in "Shoe } \\
\text { Bomb" }\end{array}$ & $12 / 01$ & [24] \\
\hline NY/Denver & Zazi & Collected HP as a precursor & $\sim 9 / 09$ & [25] \\
\hline London & Group of 6 & $\begin{array}{l}\text { Subway attempt, TATP \& } \\
\text { HP/Fuel }\end{array}$ & $7 / 05$ & [26] \\
\hline Denmark & Dukayev & $\begin{array}{l}\text { Attempted letter bomb, } \\
\text { TATP }\end{array}$ & $9 / 10$ & [27] \\
\hline MA & Robison Jr. & $\begin{array}{l}\text { Amateur Chemist, home- } \\
\text { made T ATP + Other } \\
\text { Explosives seized }\end{array}$ & '07-'08 & [28] \\
\hline $\mathrm{TX}$ & Rugo & $\begin{array}{l}\text { Killed while grinding T ATP } \\
+ \text { metals }\end{array}$ & 7/06 & [29] \\
\hline
\end{tabular}

Table 3. DSC Data (ramp rate $20 \mathrm{deg} / \mathrm{min}$ from 50 to $400^{\circ} \mathrm{C}$ )

\begin{tabular}{|c|c|c|c|c|c|c|c|c|c|c|c|c|}
\hline \multirow[b]{3}{*}{ Sample } & \multirow[b]{3}{*}{$\begin{array}{c}\% \text { wt } \\
\text { TATP }\end{array}$} & \multirow[b]{3}{*}{$\begin{array}{c}\% \text { wt } \\
\text { DADP }\end{array}$} & \multirow[b]{3}{*}{$\begin{array}{l}\text { \# of } \\
\text { Runs }\end{array}$} & \multicolumn{9}{|c|}{ DSC Events } \\
\hline & & & & \multicolumn{3}{|c|}{ TATP Melt } & \multicolumn{3}{|c|}{ DADP Melt } & \multicolumn{3}{|c|}{ Exotherm } \\
\hline & & & & $\begin{array}{c}\text { Onset } \\
\left({ }^{\circ} \mathrm{C}\right)\end{array}$ & $\begin{array}{c}\text { Heat } \\
\text { Absorbed } \\
(\mathrm{J} / \mathrm{g})\end{array}$ & $\begin{array}{l}\text { Max } \\
\text { Endo } \\
\left({ }^{\circ} \mathrm{C}\right)\end{array}$ & $\begin{array}{c}\text { Onset } \\
\left({ }^{\circ} \mathrm{C}\right)\end{array}$ & $\begin{array}{c}\text { Heat } \\
\text { Absorbed } \\
(\mathrm{J} / \mathrm{g})\end{array}$ & $\begin{array}{l}\text { Max } \\
\text { Endo } \\
\left({ }^{\circ} \mathrm{C}\right)\end{array}$ & $\begin{array}{c}\text { Onset } \\
\left({ }^{\circ} \mathrm{C}\right)\end{array}$ & $\begin{array}{c}\text { Heat } \\
\text { Released } \\
(\mathrm{J} / \mathrm{g})\end{array}$ & $\begin{array}{l}\text { Max } \\
\text { Exo } \\
\left({ }^{\circ} \mathrm{C}\right)\end{array}$ \\
\hline TATP & 100 & 0 & 7 & 95 & 85 & 97 & -- & -- & -- & 202 & 2511 & 239 \\
\hline 75/25 TATP/DADP & $82-86$ & $14-18$ & 2 & 77 & 93 & 81 & -- & -- & -- & 207 & 2775 & 240 \\
\hline 50/50 TATP/DADP & $53-61$ & $39-47$ & 2 & 78 & 55 & 81 & 96 & 49 & 105 & 207 & 2809 & 242 \\
\hline 25/75 TATP/DADP & $37-59$ & $41-63$ & 3 & 82 & 98 & 85 & -- & 62 & 112 & 197 & 3128 & 243 \\
\hline DADP & 0 & 100 & 4 & -- & -- & -- & 130 & 200 & 132 & 219 & 3253 & 251 \\
\hline $0.1: 1$ (30wt $\%), 5^{\circ} \mathrm{C}$ & 100 & 0 & 2 & 93 & 63 & 98 & - & - & -- & 184 & 2904 & 228 \\
\hline $0.1: 1$ (30wt $\%), 5^{\circ} \mathrm{C}$ & 91 & 0 & 3 & -- & 37 & 94 & -- & -- & -- & 175 & 2669 & 235 \\
\hline $0.4: 1$ (65wt\%), $25^{\circ} \mathrm{C}$ & 98 & 3 & 2 & 88 & 48 & 90 & -- & -- & -- & 96 & 2822 & 108 \\
\hline $0.8: 1$ (50wt \%), $25^{\circ} \mathrm{C}$ & 50 & 47 & 3 & 75 & 68 & 80 & -- & -- & -- & 93 & 2594 & 133 \\
\hline $0.8: 1$ (50wt\%), $25^{\circ} \mathrm{C}$ & 44 & 47 & 3 & 78 & 28 & 81 & 104 & 61 & 114 & 128 & 2905 & 147 \\
\hline $1.0: 1$ (65wt $\%), 25^{\circ} \mathrm{C}$ & 0.6 & 94 & 2 & -- & -- & -- & 125 & 72 & 128 & 133 & 2564 & 142 \\
\hline $1.2: 1$ (50wt\%), $25^{\circ} \mathrm{C}$ & 0.5 & 96 & 3 & -- & -- & -- & 124 & 99 & 128 & 149 & 2844 & 154 \\
\hline $1.8: 1$ (50wt $\%), 25^{\circ} \mathrm{C}$ & 0.1 & 91 & 2 & -- & -- & -- & 125 & 90 & 127 & 137 & 2947 & 141 \\
\hline 20wt \% 2-Pentanone & 84 & -- & 2 & 88 & 28 & 94 & -- & -- & -- & 139 & 1220 & 153 \\
\hline 20wt\% 2-Butanone & 68 & -- & 3 & 76 & 42 & 83 & -- & -- & -- & 123 & 1698 & 143 \\
\hline 10 wt $\%$ Formamide & 97 & -- & 2 & 87 & 61 & 98 & -- & -- & -- & 209 & 1952 & 242 \\
\hline
\end{tabular}


Table 4. Drop Weight Impact (1.91 kg) \& SSED Data

\begin{tabular}{|c|c|c|c|c|c|}
\hline \multirow{2}{*}{ Sample: } & \multirow{2}{*}{$\begin{array}{c}\% \text { TATP / } \\
\% \text { DADP } \\
\text { by } \\
\text { GC/ } \mu \mathrm{ECD}\end{array}$} & \multirow{2}{*}{$\begin{array}{c}\text { Melting } \\
\text { Point } \\
{ }^{\circ} \mathrm{C}\end{array}$} & \multirow{2}{*}{$\begin{array}{c}\text { Impact } \\
\mathrm{h}_{50} \\
(\mathrm{~cm})\end{array}$} & \multicolumn{2}{|c|}{ SSED Data } \\
\hline & & & & $\begin{array}{l}\text { Charge } \\
\text { Wt (g) }\end{array}$ & $\begin{array}{c}\% \text { Base } \\
\text { Rem. }\end{array}$ \\
\hline Recrystallized T ATP & $98 / 0$ & $95-96$ & 5.3 & 0.7580 & $42 \%$ \\
\hline 75/25 TATP/DADP & $86 / 18$ & $74-87$ & 6.0 & -- & -- \\
\hline 50/50 TATP/DADP & $53 / 39$ & $77-106$ & 3.4 & -- & -- \\
\hline 25/75 TATP/DADP & 37 / 41 & 83-122 & 7.6 & -- & -- \\
\hline Recrystallized DADP & $0 / 84$ & 131-133 & 12.5 & 1.2989 & $42 \%$ \\
\hline TNT & -- & - & - & 2.0000 & $37 \%$ \\
\hline PETN & -- & -- & 33.7 & 2.0000 & $26 \%$ \\
\hline HMTD & -- & -- & 4.7 & -- & -- \\
\hline $0.6: 1$ (65wt \%), $5^{\circ} \mathrm{C}$ & $94 / 0.3$ & $79-82$ & 4.6 & -- & - \\
\hline 0.8:1 (50wt\%), $5^{\circ} \mathrm{C}$ & 85 / 0.4 & 88-89 & 4.0 & -- & -- \\
\hline 1.8:1 (50wt\%), $25^{\circ} \mathrm{C}$ & $0.1 / 85$ & $108-111$ & 7.3 & -- & -- \\
\hline
\end{tabular}

Table 5. Impact (4.3 kg) Sensitivity of Wetted TATP

\begin{tabular}{|c|c|c|c|c|c|c|c|}
\hline $\begin{array}{l}\text { Drop Weight } \\
(\mathrm{cm})\end{array}$ & 5 & 100 & 100 & 100 & 100 & 100 & 100 \\
\hline Additive & None & $\mathrm{EtOH}$ & $\mathrm{EtOH}$ & $/ \mathrm{H}_{2} \mathrm{O}$ & Diesel & WD-40 & Water \\
\hline Additive $(\mu \mathrm{L})$ & -- & 200 & 200 & 100 & 200 & 200 & 200 \\
\hline Trial & \multicolumn{7}{|c|}{ FINE PARTICLES } \\
\hline 1 & G/NG & $\mathrm{G} / \mathrm{NG}$ & NG & NG & NG & G? & G \\
\hline 2 & G & NG & NG & NG & NG & NG & G \\
\hline 3 & G & NG & NG & NG & NG & G? & G \\
\hline 4 & NG & NG & & & & & \\
\hline 5 & G & NG & & & & & \\
\hline \multirow[t]{2}{*}{6} & G & NG & & & & & \\
\hline & \multicolumn{7}{|c|}{ COARSE PARTICLES } \\
\hline Conditions & & (a) & (a) & (c) & (b) & (c) & (c) \\
\hline (a) - wetted & & G & G & & G & G & G \\
\hline $\begin{array}{c}\text { (b) - soaked } 12 \mathrm{~h} \\
\text { \& wet }\end{array}$ & & NG? & G & & G & G & G \\
\hline $\begin{array}{c}\text { (c) - soaked } 12 \mathrm{~h} \\
\& \text { dry }\end{array}$ & & G & G & & G & G & G \\
\hline
\end{tabular}




\section{Figure Captions}

Figure 1. \% TATP Yield vs. molar ratio of HP (30wt\%) to acetone; 1 or 10mol\% Acid (48wt\%); $48 \mathrm{hr} ; 25^{\circ} \mathrm{C}$

Figure 2. \% TATP Yield vs. RXN Length (hr) for varying [HP]; 13.5mmols HP/Acetone; 1 mol\% Acid (48wt\%)

Figure 3. \% Total Peroxide Yield vs. RXN Temperature for varying molar ratios of acid (48wt\%) to HP (30wt\%); 13.5mmol HP /Acetone; 24hr

Figure 4. \% Total Peroxide Yield vs. Molar Ratio of Acid to 13.5mmols HP/Acetone

Figure 5. \% TATP (by GC) vs. Molar Ratio of Acid:HP; 13.5mmols HP/Acetone; 24hr; varying temp

Figure 6. \% DADP (by GC) vs. Molar Ratio of Acid (varying wt\%) to HP (varying wt\%); 13.5mmols HP/Acetone; 24hr; varying temp

Figure 7. \% DADP and \% Total Peroxide Yield vs. Molar Ratio of Acid (63wt\%) to HP (wt\% HP indicated); $13.5 \mathrm{mmols} \mathrm{HP} /$ Acetone; $25^{\circ} \mathrm{C}$; $24 \mathrm{hr}$

Figure 8. \% DADP \& \% Total Peroxide Yield vs. Water to Acid (63wt\%) molar ratio; wt\% HP indicated; $13.5 \mathrm{mmols} \mathrm{HP} /$ Acetone; $25^{\circ} \mathrm{C} ; 24 \mathrm{hr}$

Figure 9. Sulfuric Acid moles/kg water vs. HP moles/kg water - regions of DADP vs. TATP formation at $25^{\circ} \mathrm{C} ; 13.5 \mathrm{mmols} \mathrm{HP} /$ Acetone; $24 \mathrm{hr}$

Scheme 1. Triacetone Triperoxide (TATP) and Diacetone Diperoxide (DADP) 
Figure 1. \% TATP Yield vs. molar ratio of HP (30wt\%) to acetone; 1 or 10mol\% Acid (48wt\%); $48 \mathrm{hr} ; 25^{\circ} \mathrm{C}$
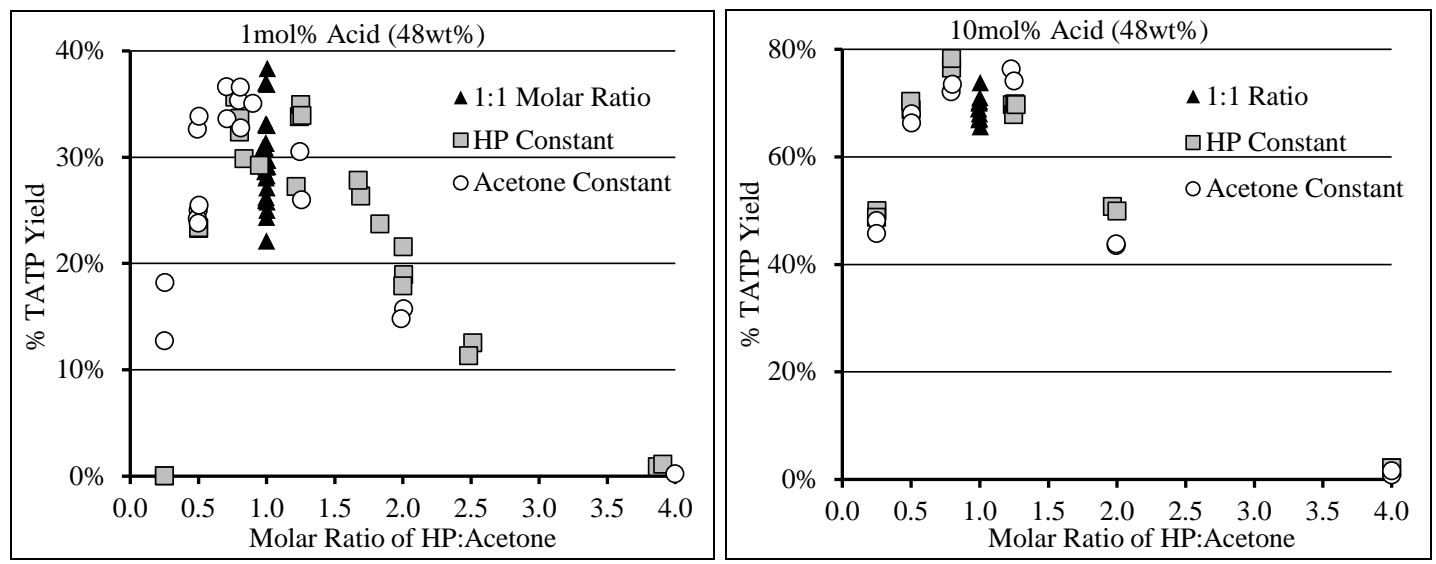
Figure 2. \% TATP Yield vs. RXN Length (hr) for varying [HP]; 13.5mmols HP/Acetone; 1 mol\% Acid (48wt\%)

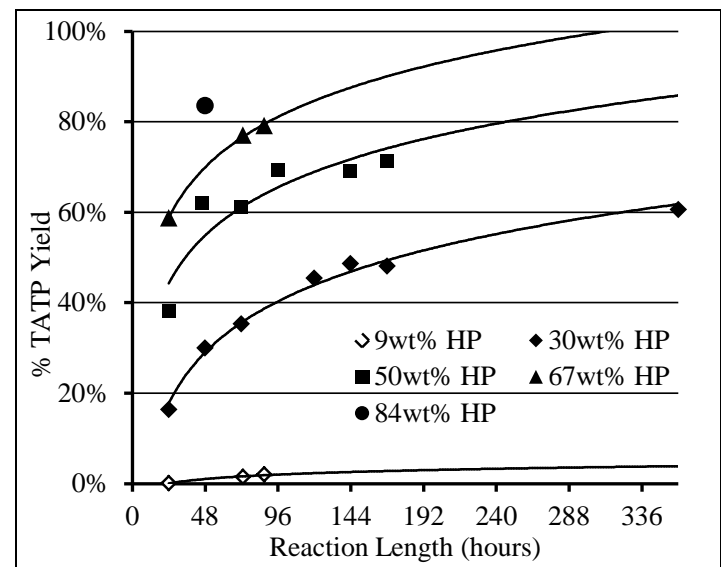


Figure 3. \% Total Peroxide Yield vs. RXN Temperature for varying molar ratios of acid (48wt\%) to HP (30wt\%); 13.5mmol HP /Acetone; 24hr

* - at $40^{\circ} \mathrm{C}$, 3wt $\%$ of the yield was DADP

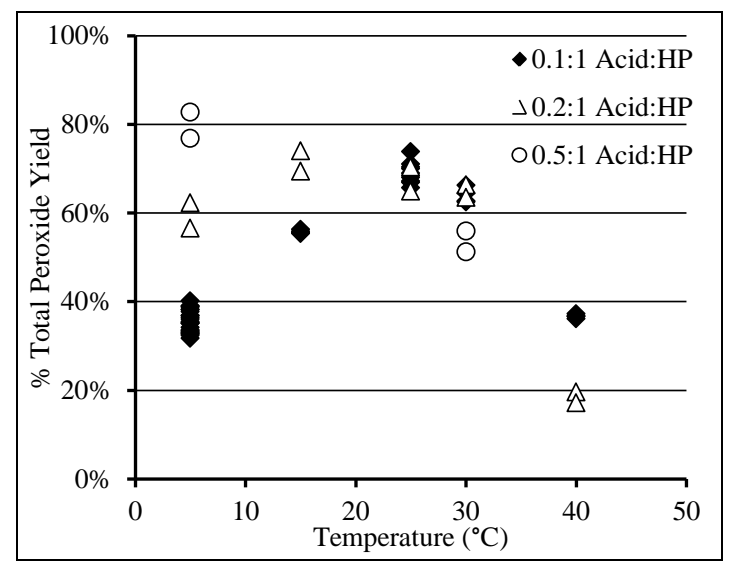


Figure 4. \% Total Peroxide Yield vs. Molar Ratio of Acid to 13.5mmols HP/Acetone * - Left graph is an expanded view of 0-0.5 ratio region
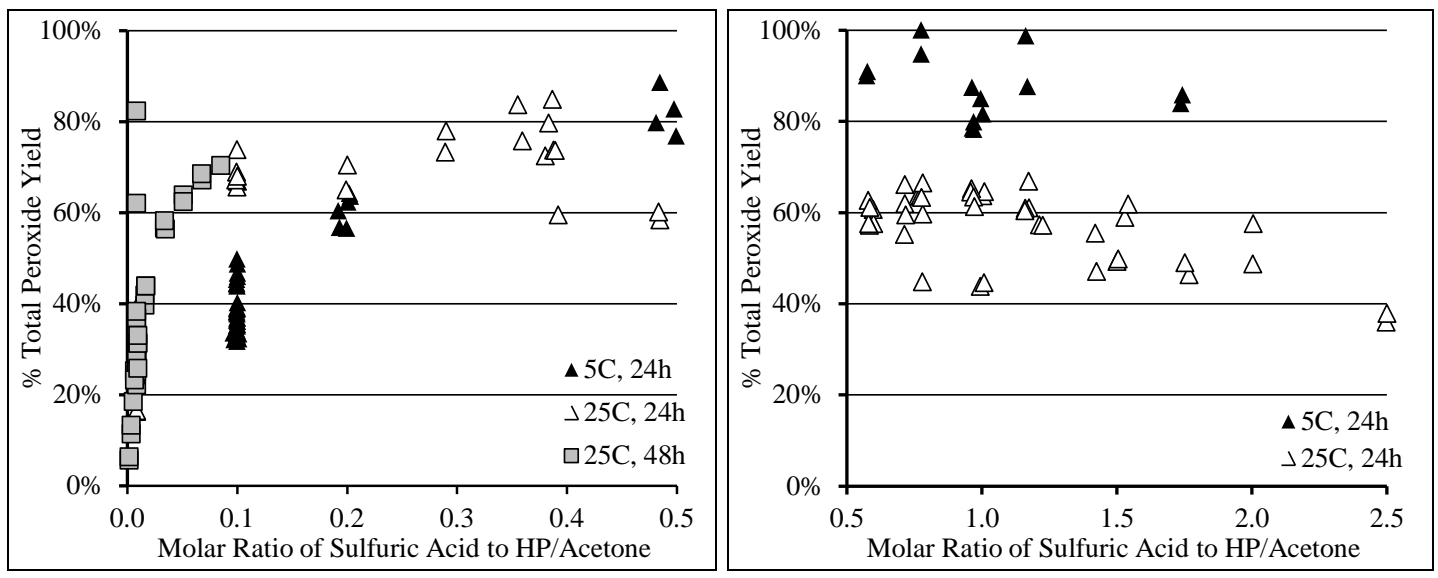
Figure 5. \% TATP (by GC) vs. Molar Ratio of Acid:HP; 13.5mmols HP/Acetone; 24hr; varying temp

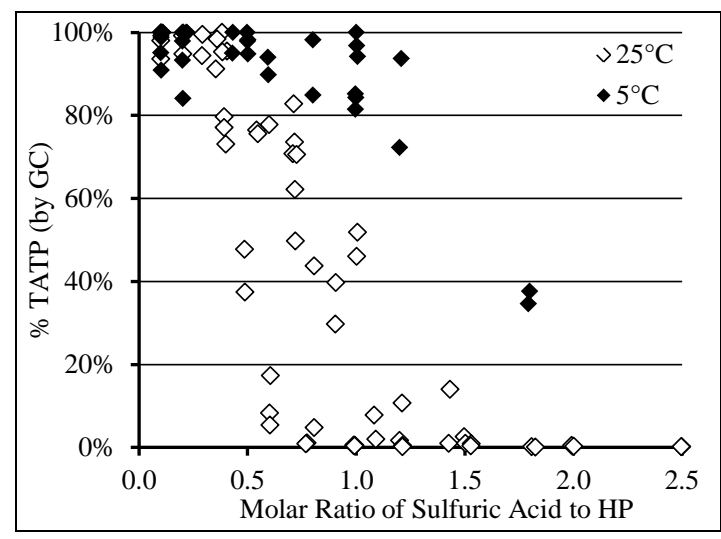


Figure 6. \% DADP (by GC) vs. Molar Ratio of Acid (varying wt\%) to HP (varying wt\%); 13.5mmols HP/Acetone; 24hr; varying temp

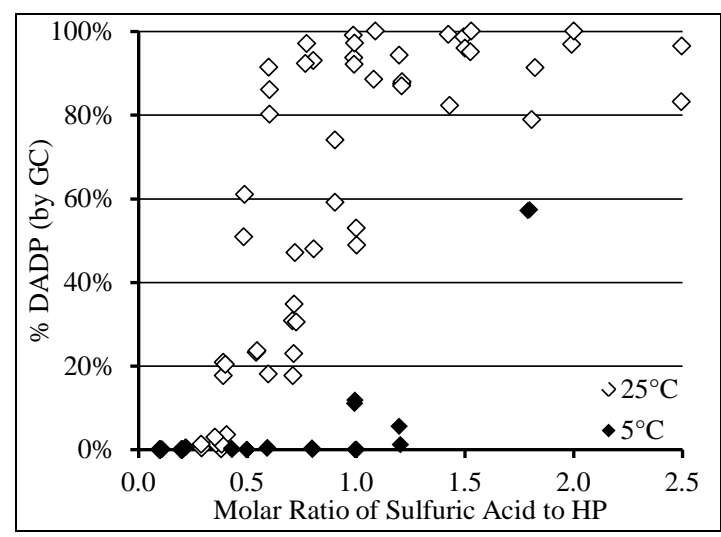


Figure 7. \% DADP and \% Total Peroxide Yield vs. Molar Ratio of Acid (63wt\%) to HP (wt\% $\mathrm{HP}$ indicated); $13.5 \mathrm{mmols} \mathrm{HP} /$ Acetone; $25^{\circ} \mathrm{C}$; $24 \mathrm{hr}$
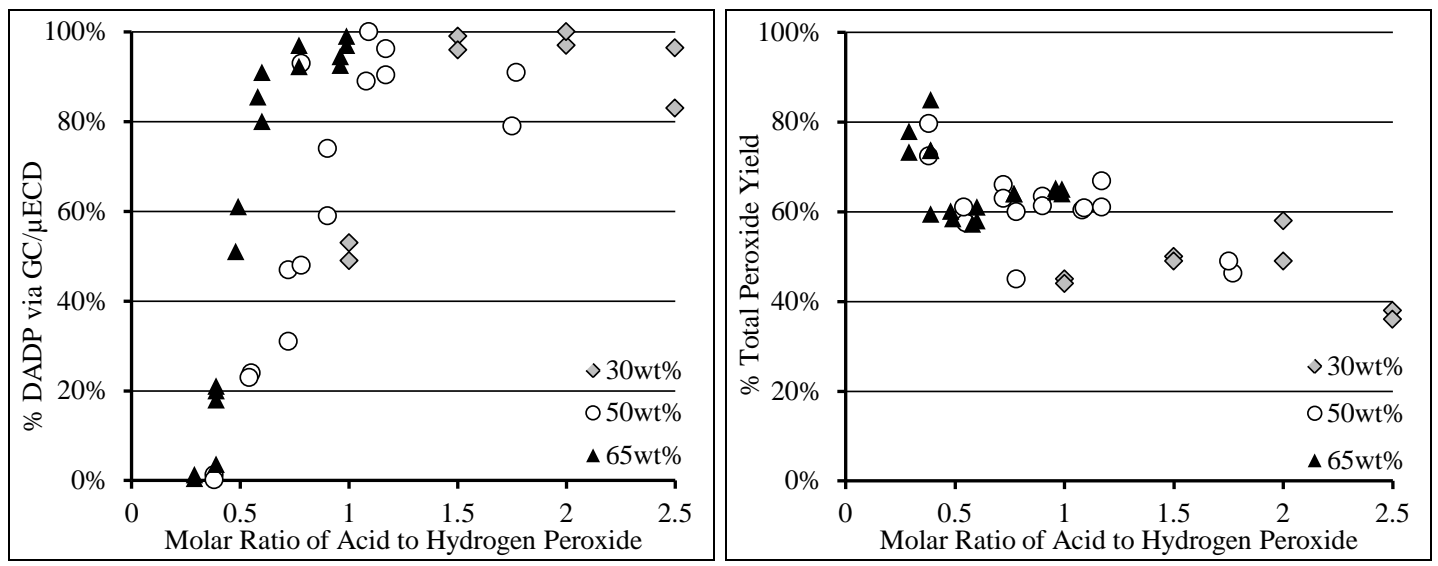
Figure 8. \% DADP \& \% Total Peroxide Yield vs. Water to Acid (63wt\%) molar ratio; wt\% HP indicated; $13.5 \mathrm{mmols} \mathrm{HP} /$ Acetone; $25^{\circ} \mathrm{C} ; 24 \mathrm{hr}$
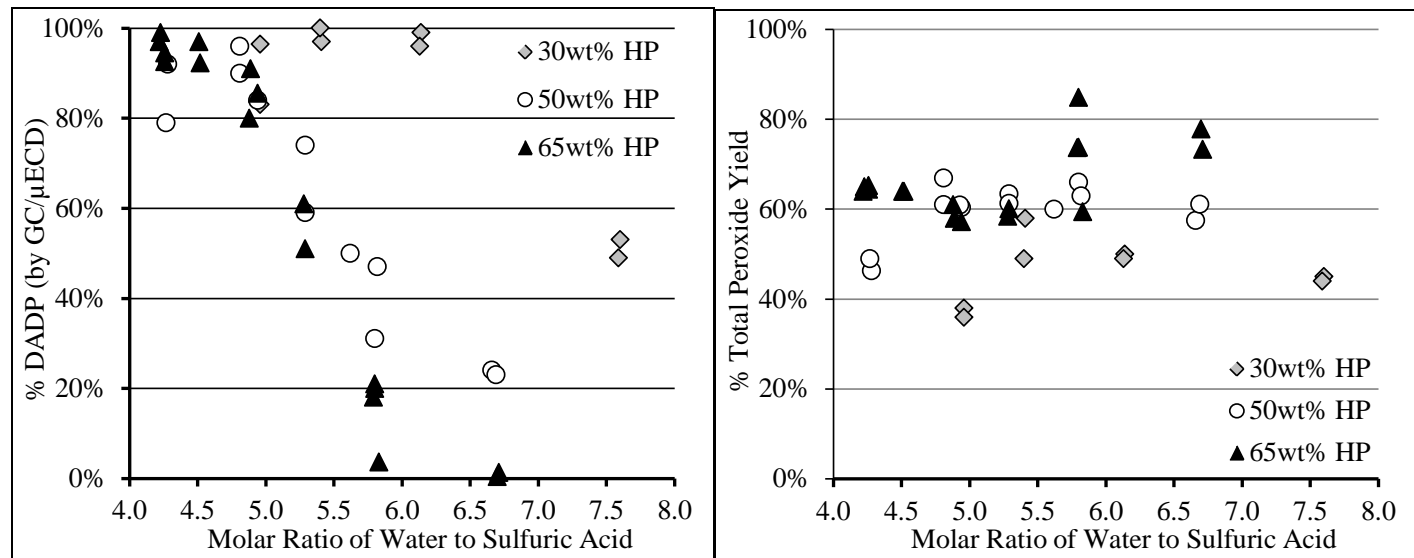
Figure 9. Sulfuric Acid moles/kg water vs. HP moles/kg water - regions of DADP vs. TATP formation at $25^{\circ} \mathrm{C} ; 13.5 \mathrm{mmols} \mathrm{HP} /$ Acetone; $24 \mathrm{hr}$

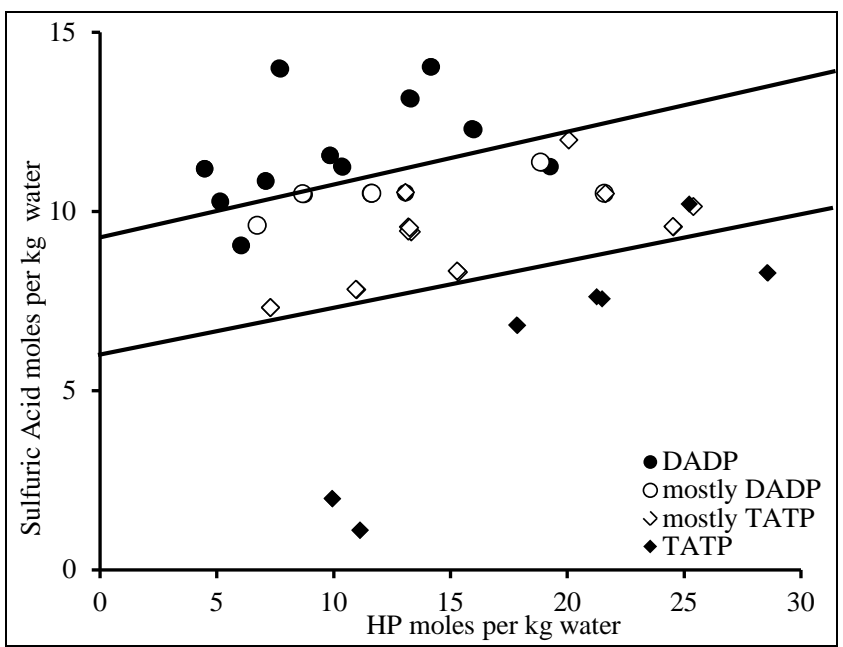



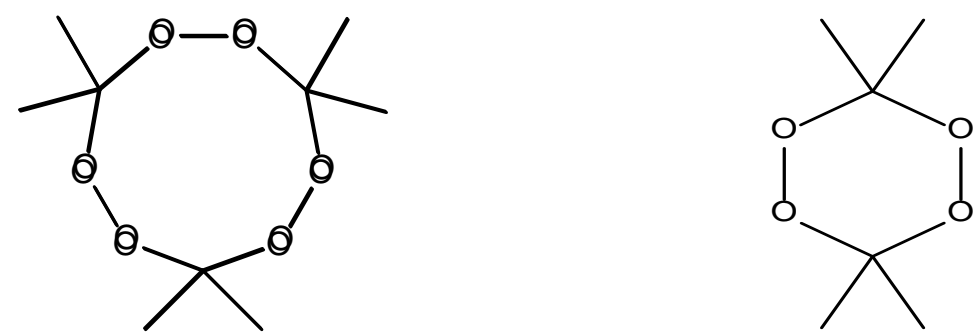

Scheme 1. Triacetone Triperoxide (TATP) and Diacetone Diperoxide (DADP) 